48 (1) | 2019

Varia

\title{
Navegación indígena en el puerto de Paita. Abasto y contrabando
}

Navigation indigène dans le port de Paita. Approvisionnement et contrebande Indigenous navigation in the port of Paita. Supply and smuggling

\section{Antonio Jaramillo Arango}

\section{(2) OpenEdition}

Journals

Edición electrónica

URL: http://journals.openedition.org/bifea/10397

DOI: $10.4000 /$ bifea. 10397

ISSN: 2076-5827

Editor

Institut Français d'Études Andines

Edición impresa

Fecha de publicación: 1 abril 2019

Paginación: 39-55

ISSN: 0303-7495

Referencia electrónica

Antonio Jaramillo Arango, "Navegación indígena en el puerto de Paita. Abasto y contrabando », Bulletin de l'Institut français d'études andines [En línea], 48 (1) | 2019, Publicado el 08 abril 2019,

consultado el 04 noviembre 2020. URL : http://journals.openedition.org/bifea/10397 ; DOI : https:// doi.org/10.4000/bifea.10397

\section{(c) $(1)$}

Les contenus du Bulletin de l'Institut français d'études andines sont mis à disposition selon les termes de la licence Creative Commons Attribution - Pas d'Utilisation Commerciale - Pas de Modification 4.0 International. 


\title{
Navegación indígena en el puerto de Paita. Abasto y contrabando
}

\author{
Antonio Jaramillo Arango*
}

\begin{abstract}
Resumen
En este artículo buscamos entender la importancia de la navegación indígena en la costa norte del Perú en la época virreinal. Las balsas del pueblo de indios de San Lucas de Colán llegaban diariamente al puerto español de Paita para proveerlo de agua y alimento. A través de un caso de contrabando que involucra dos embarcaciones francesas, registrado en 1707 en Paita, se explora la capacidad de las balsas indígenas para participar en el comercio legal e ilegal de la ruta que unía Saint-Malo, los puertos americanos sobre el Pacífico y el Lejano Oriente. Se presenta la contextualización del caso y luego se sacan conclusiones sobre el alcance de la participación indígena. Finalmente, se presenta la versión paleográfica del documento más relevante de los consultados en la investigación.
\end{abstract}

Palabras clave: navegación indígena, contrabando, Saint-Malo

\section{Navigation indigène dans le port de Paita. Approvisionnement et contrebande}

\section{Résumé}

L'objectif poursuivi dans cet article es de comprendre l'importance de la navigation indigène le long de la côte nord du Pérou à l'époque de la vice-royauté. Les radeaux du village indien de San Lucas de Colán abordaient quotidiennement le port espagnol de Paita, pour l'approvisionner en eau douce et en aliments. À travers l'étude d'un cas de contrebande impliquant deux vaisseaux français, signalé en 1707 à Paita, on explore la capacité des radeaux indigènes à prendre part à des échanges légaux et illégaux dans le cadre de la route maritime allant de Saint-Malo à l'Extrême-Orient en passant par les ports américains de la côte pacifique. Le cas est contextualisé, puis l'on en tire des conclusions

Becario posdoctoral del Instituto de Investigaciones Históricas, Universidad Nacional Autónoma de México (Circuito Mario de la Cueva s/n. Zona Cultural, Ciudad Universitaria. Delegación Coyoacán, 04510. Ciudad de México, México). E-mail: a.jaramillo232@gmail.com 
sur l'ampleur de la participation indigène. Finalement, on présente la version paléographique du document le plus pertinent parmi ceux consultés pour cette recherche.

Mots-clés : navigation indigène, contrebande, Saint-Malo

\title{
Indigenous navigation in the port of Paita. Supply and smuggling
}

\begin{abstract}
This article seeks to understand the importance of indigenous navigation on the northern coast of Peru during the Viceregal Period. Every day the rafts of the village of Indians of San Lucas de Colán arrived at the Spanish port of Paita to provide water and food. Through a smuggling case registered in 1707 in Paita involving two French vessels, the article explores the capacity of the indigenous rafts to participate in the legal and illegal trade along the route that linked Saint-Malo, the American ports on the Pacific and the Far East. The article presents a contextualization of the case and draws conclusions on the importance of indigenous participation. In addition, the article presents the paleographic version of the most relevant document consulted in this research.
\end{abstract}

Keywords: Indigenous Navigation, Smuggling, Saint-Malo

La navegación indígena en América durante la época virreinal es un tema del que se disponen pocas fuentes. Prácticamente ausente de los registros legales españoles, la mayor parte de la información con la que cuentan los investigadores proviene de crónicas de viajeros europeos, que registraban con ánimo curioso todo aquello que les parecía singular de las tierras americanas. Hablando específicamente de la costa norte del Perú y de la costa ecuatoriana, existen varias descripciones detalladas de balsas, embarcaciones indígenas que disponían de velas y timones. Aunque estas descripciones son bastante precisas, incluso muchas cuentan con dibujos explicativos, no dan mayor información sobre el uso cotidiano de las balsas ni de cómo estas eran utilizadas por los indígenas. Algunas fuentes virreinales que describen su funcionamiento son muy conocidas, como el escrito de Girolamo Benzoni (1985), el de Jorge Juan y Antonio de Ulloa (1748: lib IV, cap. IX) o el de Antonio de Alcedo (1788: 319-320). No es mi intención insistir en fuentes muy conocidas y utilizadas por numerosos investigadores contemporáneos de manera bastante rigurosa, sino complementar este tipo de información con otra más cotidiana que da cuenta de cómo la tecnología náutica indígena era usada por los pueblos que la controlaban y qué impactos tuvo dentro de la sociedad virreinal. Conocer la práctica de la navegación indígena no solo es importante para tener un panorama más completo de la vida virreinal en los territorios americanos, sino que es indispensable para conocer muchos fenómenos del tráfico marítimo en el continente. Tomando un documento inédito proveniente del Archivo Regional de Piura (ARdP), Perú, y comparando su información con otras fuentes publicadas y 
conocidas, el presente artículo da un panorama de la navegación indígena durante el periodo virreinal en el puerto de Paita, específicamente a finales del siglo XVII y comienzos del siglo XVIII.

\section{EL EMPLAZAMIENTO DEL PUERTO DE PAITA}

La fundación del puerto de Paita está sumida en el misterio. La ciudad fue asolada por numerosos ataques de piratas y por incendios y mucha de su documentación temprana ha desaparecido para siempre. No obstante, a finales del siglo XIX, Manuel Gómez Laines (o Lainez) afirmó haber encontrado el acta de fundación del «tambo de Payta» adherida a un misal en el convento de San Lucas de Colán. Este edificio se quemó en 1888, por lo que el documento está irremediablemente perdido (Moya Espinoza, 1994: 117). Sin embargo, nos queda la versión de Gómez Laines quien resumió algunos pasajes de la fundación de la ciudad a partir del acta y de algunos papeles que también se quemaron cuando su domicilio se incendió en 1884. Según este relato, en 1532 José Martínez de Ubilús fundó un asentamiento en la bahía donde el piloto Bartolomé Ruiz había decidido atracar los barcos para repararlos: la playa de varadero, donde gobernaba el cacique de «Payta»; razón por la cual este lugar recibió el nombre de San Francisco de Payta de Buena Esperanza (Moya Espinoza, 1994: 117-118).

Si bien el relato de Gómez Laines carece de exactitud histórica y se duda de la autenticidad de los documentos que dijo consultar (Moya Espinoza, 1994: 118), esta es la versión «oficial» sobre la fundación de Paita (Zúñiga de Riofrío, 2011). Al parecer, el emplazamiento del puerto de Paita en la bahía del mismo nombre fue escogido por la ventaja de atraer a los barcos europeos de gran calado y por las facilidades que el territorio ofrecía para su defensa (Sears, 1895). Por estas razones, San Francisco de Paita de Buena Esperanza se volvió el puerto de mayor importancia del norte peruano durante todo el periodo virreinal. Paita fue un punto recurrente del comercio entre Lima y Panamá y servía de puerto comercial a una amplia zona del norte peruano y del sur ecuatoriano, sobre todo durante el siglo XVIII (Jaramillo, 2002).

No obstante lo anterior, la ubicación no era la más adecuada para un asentamiento humano. Debido al fenómeno climatológico conocido como «inversión térmica», en la costa peruana la lluvia está prácticamente ausente durante todo el año. Además, Paita no está situada en la desembocadura de algún río que baje de la sierra, por lo que no cuenta con un valle fértil que le permita abastecerse de alimentos y agua dulce. Por estas razones, todos los recursos alimenticios y el agua para consumo humano tenían que ser transportados desde los valles cercanos hasta el puerto. La ubicación del poblado, bajo un pronunciado barranco, hacía que el aprovisionamiento por tierra fuera mucho más dificultoso que por mar, por lo que la supervivencia de los habitantes de Paita dependía del comercio y transporte marítimos. 


\section{ABASTECIMIENTO INDÍGENA AL PUERTO ESPAÑOL}

Quienes suministraban agua dulce y alimento a Paita eran los habitantes de los pueblos de indios cercanos al puerto. Dentro de estos resalta San Lucas de Colán, ubicado a tan solo diez millas al norte. Sobre este suministro indígena aún existen varios testimonios. Citaré dos de los más elocuentes pues demuestran que el transporte de mercancías de Colán a Paita en balsas de tradición indígena se practicó por más de tres siglos. El primero pertenece a las relaciones geográficas del siglo XVI:

Tiene gran fondo el dicho puerto [Paita] y entradas y salidas muy limpias, aunque el agua y leña es de acarreo por la mar en balsas; porque la población del dicho puerto está en un arenal seco, y por el trato y frecuentación están allí españoles y naturales que proveen de todo lo necesario a los navíos que allí llegan (Jiménez de la Espada, 1885: 226).

La segunda referencia proviene del texto de Justo Zaragoza, perteneciente a la expedición de Alejandro Malaspina y José Bustamante y Guerra, llevada a cabo a finales del siglo XVIII:

Provisión y agua de Colán para Paita.- La entera falta de agua en Paita y el llover sino raras veces, por ser un país de valles, causa una total aridez en su territorio. Le precisa tener una continua comunicación con Colán, población situada en un terreno fértil [...]. Este le provee por medio de balsas de agua en botijas, como igualmente de verduras y carne $[\ldots]$ (Zaragoza, 1885: 544).

Estas dos referencias demuestran que, desde el siglo XVI hasta el final del periodo virreinal, el puerto español de Paita dependió de la provisión de agua y alimento de las balsas indígenas de Colán.

Este comercio entre los indígenas de Colán y los españoles de Paita daba a los primeros una autonomía económica notable. Un ejemplo de esto es el excepcional testamento dejado por don Luis de Colán en 1622 en el que se da testimonio no solo de la gran riqueza de este cacique indígena, que contaba con esclavos de origen africano y vestidos traídos desde el Lejano Oriente, sino de sus lazos comerciales con Paita, Piura, Chiclayo, Guayaquil, la isla de la Puná, Loja, Cuenca, Zaruma, Bracamoros y Salinas (Rostworowski, 2004). Muchos personajes de Colán y de Paita debían a don Luis altas sumas de dinero y bienes, por lo que se puede inferir el poder de este cacique en toda la región1. Personajes de gran importancia dentro de la vida virreinal, como el cura y el teniente corregidor de Paita, arrendaban casas en el puerto que pertenecían a don Luis (Rostworowski, 2004: 188). La fortuna de este personaje se debía a la producción de alimentos y sal y a su comercialización con Paita y otros lugares. En su testamento indica que Juan Gonzales, vizcaíno, le debe veinte patacones que le prestó por el flete de una balsa cargada de sal enviada a Guayaquil (Rostworowski, 2004: 201). Un

${ }^{1}$ ARdP, Corregimiento, Caja N. 1, Exp. N. 0011, Deudas de don Diego de Belasco, ff. 24r, 32v. 
descendiente de don Luis, don Sebastián, mantenía gran parte de sus relaciones comerciales y riqueza (Elías Lequernaqué, 2008). En el Archivo Regional de Piura se conservan varios testamentos de indígenas de Colán que atestiguan la cantidad de bienes atesorados por otros habitantes de este pueblo, incluso contando con esclavos de origen africano, lo que indica que la riqueza indígena no se restringía únicamente a don Luis y su núcleo familiar2.

El otro punto que merece mención es la forma en la que se lleva a cabo este abastecimiento al puerto: mediante balsas. Aunque una acepción de la palabra «balsa» tiene origen europeo, su significado difiere en Europa y en América. El Diccionario de Autoridades de 1726 de la Real Academia Española da cuenta de esta ambigüedad. La primera entrada de la palabra balsa es: «Charco formado del concurso de aguas detenidas à manéra de estanque ò lagúna», e indica un posible origen hebreo de la palabra. La segunda entrada dice lo siguiente: «Espécie de embarcación que usan los Indios comúnmente, la qual se compóne de unos madéros juntos con otros, ligados fuertemente sin arte, árbol ni velas...» (Real Academia Española, 1726).

Estas dos definiciones muestran que en el contexto americano la palabra «balsa» se está refiriendo a un tipo de embarcación indígena. Es posible que esta palabra sea un préstamo lingüístico de un idioma indígena cuyo origen se ha perdido y, al haber una palabra homónima en castellano, no parezca extraña a los españoles. En algunos vocabularios y lexicones se registra la palabra «balsa» como un indigenismo de origen americano, seguramente en la segunda acepción del Diccionario de Autoridades (Hernández, 1996: 56).

Las balsas a las que se están refiriendo Zaragoza y el testamento de don Luis son muy especiales y existen varias descripciones de este tipo de embarcaciones. Dentro de la misma expedición de Alejandro Malaspina y José Bustamante y Guerra se elaboró un dibujo de estas barcas en la desembocadura del río Guayas, actual Ecuador (fig. 1). Joris van Spilbergen, quien pasó por Paita a principios del siglo XVII, también dejó su ilustración de la bahía en la que se aprecia una de estas balsas indígenas (fig. 2). La comparación entre estas dos imágenes muestra tres fenómenos de especial interés: por un lado, desde el Ecuador hasta la costa norte del Perú era relativamente común encontrarse con balsas indígenas de estas características; por otro lado, la distancia temporal entre los dibujos (casi 200 años) demuestra una continuidad histórica en el uso de este tipo de tecnología y, por último, las diferencias entre las dos embarcaciones representadas señalan que existieron múltiples naves que, siguiendo un patrón común, mostraban una gran variedad; por ejemplo, la existencia de velas triangulares para aprovechar el viento hacia varias direcciones (como se aprecia en la fig. 2) o cuadras para movilizar más cargamento (fig. 1), la posibilidad de adecuar la embarcación con una cabina para protección de tripulantes y mercancías (característica presente en la fig. 1 y ausente en la fig. 2), entre muchas otras variables posibles. 


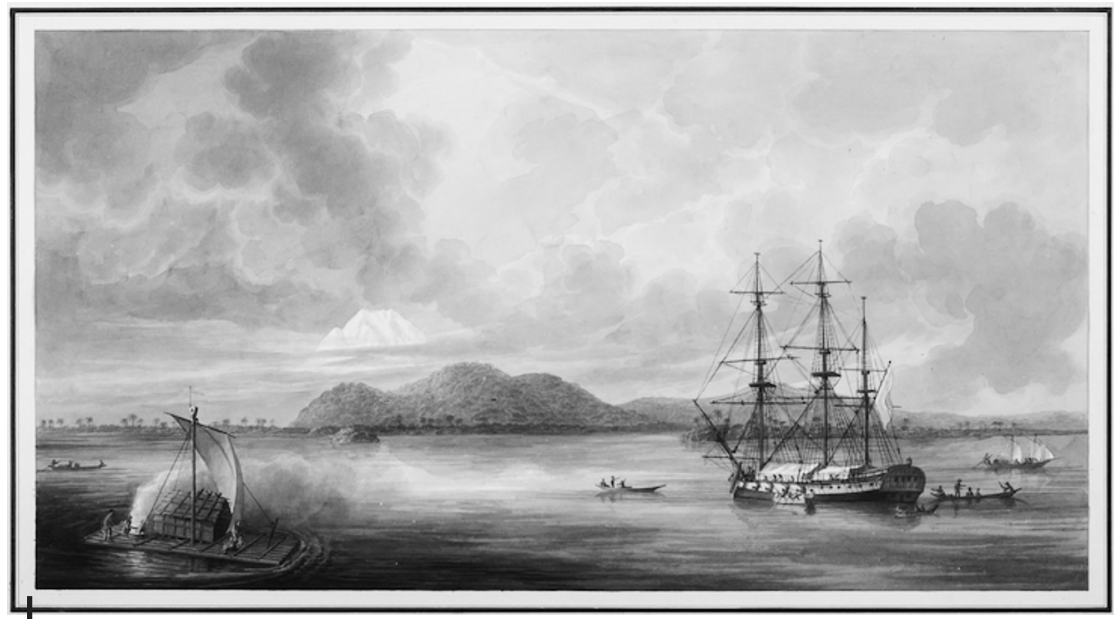

Figura 1 - Desembocadura del río Guayas donde se aprecia una balsa indígena propulsada a vela, atribuida a la expedición de Alejandro Malaspina y José Bustamante y Guerra

(C) Museo de América, Madrid

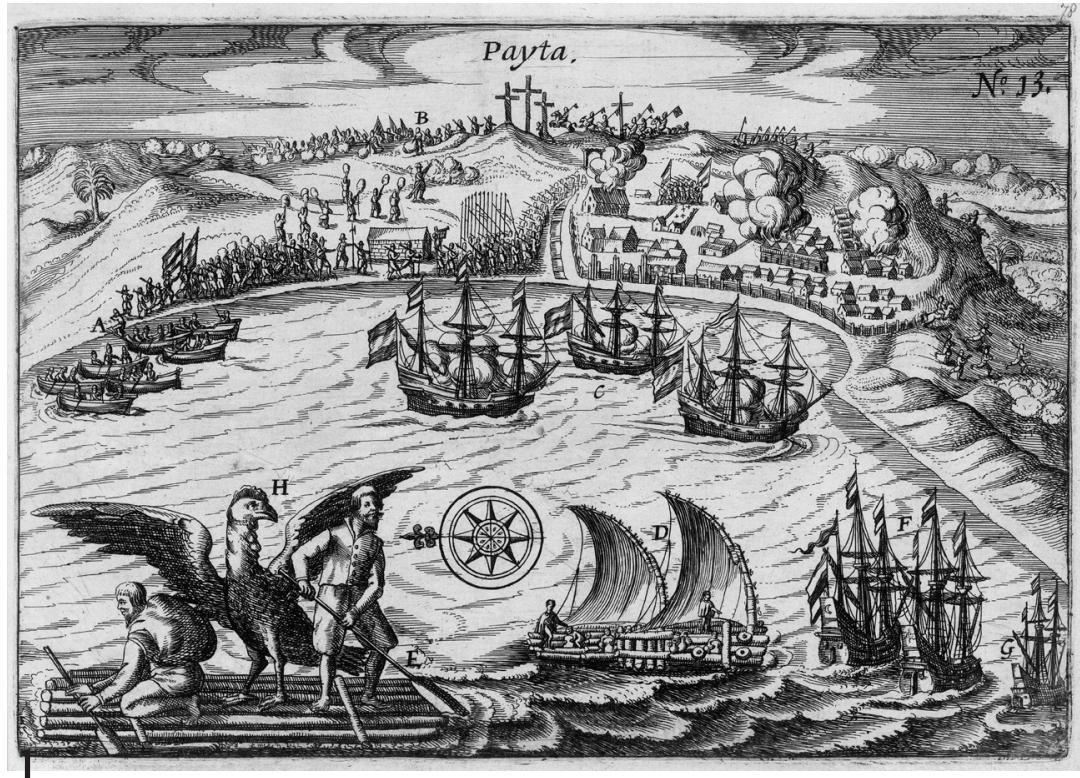

Figura 2 - Dibujo descriptivo de Paita de Joris van Spilbergen

El punto (D): «Is one of the savages' vessels, called balsem. Here they have fish aboard, and they can sail swiftly with these vessels in the wind» («Es una de las naves de los salvajes llamadas balsem. Aquí ellos tienen pescado a bordo y pueden navegar rápidamente con estas naves cuando hay viento») (Spilbergen, 1906: plate N. 13).

(C) Cortesía de la John Carter Brown Library 
Contrariamente a la simplicidad que remarca el Diccionario de Autoridades, las balsas indígenas de la costa noroccidental de Sudamérica contaban con un complejo sistema de velas latinas o cuadras y guares (que servían como quilla y como timón) que les permitían viajar eficientemente aún en contra de los vientos y las corrientes (Juan \& Ulloa, 1748: lib. IV, cap. IX). Gracias a estas embarcaciones, los indígenas americanos comerciaban desde Perú hasta Ecuador y muy posiblemente la mayoría de los contactos comerciales de don Luis de Colán con la audiencia de Quito (Guayaquil, la isla de la Puná, Loja, Cuenca, Zaruma, Bracamoros y Salinas) se daban por el transporte de mercancías en estas balsas. Además de su función comercial, algunas embarcaciones con estas características sirvieron para la pesca. Los diferentes usos explican también la diferencia formal que se aprecia en algunas descripciones de las balsas (ver, por ejemplo, las figs. 1 y 2 y la descripción de las imágenes de Benzoni, 1985): unas balsas más pequeñas para las faenas pesqueras y otras más grandes con velas de mayor envergadura para las expediciones comerciales. En la segunda mitad del siglo XX, en Sechura (al sur de Paita), se organizaban expediciones comerciales a Guayaquil en este tipo de embarcaciones (Andritzky, 1987). Las balsas se usan hoy en día en San Lucas de Colán, pero exclusivamente para la pesca (fig. 3).

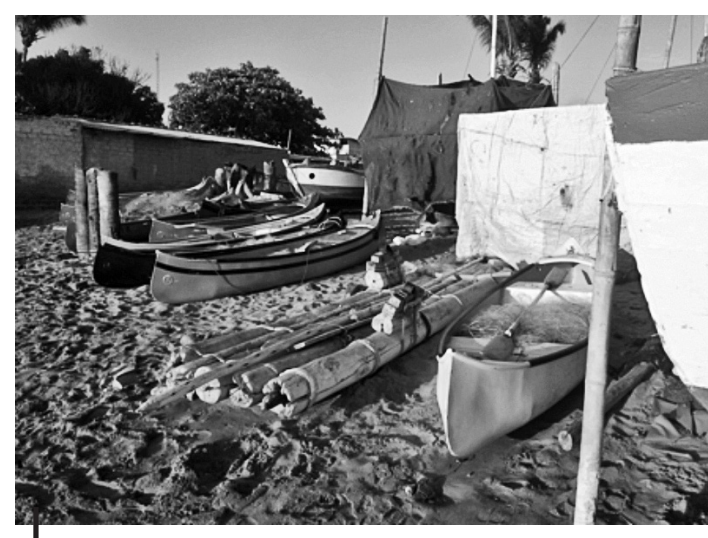

Figura 3 - Balsa actual usada para la pesca en la playa de San Lucas de Colán

(c) Antonio Jaramillo Arango (2016)

Fue dentro de este esquema general en el que los indígenas abastecían al puerto español y por esto obtenían grandes beneficios económicos (los habitantes de San Lucas de Colán y otros pueblos balseros como Sechura se relacionaron con las autoridades españolas de Paita). Esta relación, aunque mutuamente ventajosa, no estaba exenta de tensiones. Un documento excepcional del Archivo Regional de Piura nos permite conocer un poco la cotidianidad en el puerto de Paita y cómo los indígenas de Colán y otros pueblos balseros de la región usaban su tecnología de navegación.

\section{LA LLEGADA DE DOS EMBARCACIONES FRANCESAS AL PUERTO DE PAITA}

El 20 de enero de 1707, dos embarcaciones francesas llegaron a la bahía de Paita. Desde el siglo XVI, el Pacífico era visitado por numerosos navegantes de diferentes nacionalidades europeas. Paita sufrió particularmente ataques de piratas, como el de Thomas Cavendish en 1587 que quemó la totalidad del puerto español (Hakluyt, 2015: 32). La llegada de embarcaciones extranjeras, aunque no fueran formalmente reconocidas como piratas, representaba un problema para las 
autoridades portuarias, pues aunque las dos Coronas estaban oficialmente en paz para la época, el comercio francés en puertos peruanos y chilenos representaba un detrimento directo a las arcas reales y era considerado ilegal. Siguiendo una ruta que salía desde Saint-Malo, en Francia, ciertas embarcaciones se abastecían en puertos españoles sobre el Pacífico para emprender la travesía hasta el Lejano Oriente. A su regreso, estos comerciantes franceses inundaban el mercado peruano con objetos asiáticos, con los que obtenían grandes cantidades de plata. Este circuito era tan rentable que, entre 1680 y 1718, el comercio ilegal francés fue mucho más grande que las transacciones españolas y la feria de Portobelo se vio gravemente afectada por este fenómeno (Bonialian, 2012: 232).

Aunque las autoridades españolas hacían un gran esfuerzo por impedir el comercio ilegal francés, este no hubiera tenido las dimensiones que alcanzó sin un apoyo local generalizado. Incluso, a partir de la segunda década del siglo XVIII, comerciantes americanos compraron algunas embarcaciones a los navegantes franceses con las que ellos mismos emprendían operaciones de contrabando hacia otros puntos de la costa pacífica americana utilizando una ruta ya explorada desde siglos anteriores (Bonialian, 2012: 237, 241). Paita fue uno de los puertos en los que se realizaba el comercio con los franceses, aunque no fue una de las plazas que más visitaban. Concepción y Valparaíso en Chile y Pisco y Callao en Perú eran lugares de abastecimiento y venta de productos más frecuentados por los contrabandistas en la ruta hacia el Lejano Oriente (Bonialian, 2012: 235).

En este contexto llegaron las dos embarcaciones francesas a la bahía de Paita. Para frenar el posible contrabando, el teniente del puerto, Antonio Fernández de Quiñones, ordenó que nadie tuviera contacto con los marinos franceses:

Por tanto arreglándome

a dichas r[eale]s leies y bando prohivo, mando y defiendo que persona alguna no se atreva a comprar, trocar, cambiar ni en manera alguna negociar con los dichos franceses aunque sea a título y ro color de darles por sus géneros vastim[en]tos y por las mercaderías que los franceses Ilaman Bagatelas

[...] y so las mismas penas mando que ningúno sea osado a embarcarse a bordo de los dichos vageles, y que los capitanes maestres dueños de vageles contramaestres arraeces de varcas, lanchas, canoas, barquillas y balsas 3 no se atrevan a abordar ni llegar con sus embarcaciones maiores y menores a dichos vageles franceses 4 .

3 La variedad en las embarcaciones nombradas demuestra todo un complejo sistema de navegación que involucraba diferentes tipos de naves.

4 ARdP, Corregimiento, Caja N. 43, Exp. N. 0891, Expediente seguido por don Francisco Migueles sobre las embarcaciones francesas que han Ilegado a Paita, ff. 1v, $1 \mathrm{r}$. 
El castigo para quien desobedeciera estas órdenes era el pago de «quatro mil pesos»», pero si además el transgresor era indígena:

[...] que los indios dueños del agua observen lo mismo so pena de doscientos azotes, cortarles los cavellos y diez años de destierro, a sacar piedra a la isla de el Callao, cuyas penas se ejecutaran inmediatamente en las transgresiones 5 .

Llama la atención que el castigo fuera más fuerte si el infractor era indígena, y es que los balseros locales estaban en una posición privilegiada para poder contrabandear con los franceses. Por la cotidianidad de sus viajes, las embarcaciones indígenas no eran registradas por las autoridades portuarias (en los registros del puerto de 1691 y 1727, que son los que se conservan en el Archivo Regional de Piura, no aparece ninguna balsa indígena) 6 y en el recorrido desde Colán hasta Paita tendrían forzosamente que pasar cerca de las embarcaciones francesas. Vale la pena resaltar que se refieren a los indígenas como los dueños del agua, lo que indica su posición como abastecedores del puerto.

Al no poder obligarlos a partir, la estrategia de los españoles fue aislar a los franceses y que el hambre sea el que los obligue a zarpar. Las autoridades españolas esperaban que los navegantes franceses, sin posibilidad legal de aprovisionarse, tuvieran que irse a otro lugar en búsqueda de comida. Sin embargo, bajo la sospecha de que pudieran obtener abastecimiento de forma ilegal, las autoridades pusieron vigilantes en los cerros cercanos a la ciudad para asegurarse de que ninguna embarcación local entrara en contacto con los franceses o de que estos mismos desembarcaran?

\section{CONTRABANDO INDÍGENA}

A pesar de todas las prevenciones de las autoridades españolas, nueve días después de la llegada de las embarcaciones francesas al puerto se registra un incidente que involucra balsas indígenas de San Lucas de Colán. Francisco Migueles, proveniente de la ciudad de Piura, dio testimonio — corroborado por el escribano del cabildo - de haber visto dos balsas indígenas — cargadas de provisiones de agua y comida - entrar en contacto con las embarcaciones francesas. Sin embargo, según estos testimonios, las balsas indígenas se habrían quedado sin viento y fueron los marinos europeos quienes remolcaron las naves indígenas para tomar su cargamento por la fuerza ${ }^{8}$.

5 ARdP, Corregimiento, Caja N. 43, Exp. N. 0891, Expediente seguido por don Francisco Migueles sobre las embarcaciones francesas que han llegado a Paita, f. $1 \mathrm{r}$.

6 ARdP, Causas ordinarias, Legajo 43, Exp. N. 0890, Visita de embarcaciones que entran y salen de Paita. Enero-julio, 1691; ARdP, Corregimiento, Caja N. 43, Exp. N. 0892, Expediente civil relacionado con la entrada y salida de embarcaciones del puerto de Paita, 1727.

7 ARdP, Corregimiento, Caja N. 43, Exp. N. 0891, Expediente seguido por don Francisco Migueles sobre las embarcaciones francesas que han Ilegado a Paita, f. $1 \mathrm{r}$.

8 ARdP, Corregimiento, Caja N. 43, Exp. N. 0891, Expediente seguido por don Francisco Migueles sobre las embarcaciones francesas que han Ilegado a Paita, ff. $5 \mathrm{v}, 5 \mathrm{r}$. 
La actitud pasiva que en los testimonios se otorga a los tripulantes indígenas de las balsas parece poco verosímil. Por un lado, las balsas no solo dependían de sus velas para la propulsión. Girolamo Benzoni es explícito en describir que en momentos de poco viento los balseros usaban remos para mover las embarcaciones (Benzoni, 1985: 112). Por eso, aunque se hayan quedado sin viento podían seguir su recorrido. Por otro lado, los mismos testigos dan cuenta de haber visto tres balsas haciendo el recorrido y tan solo dos de ellas parar justo en frente de los barcos en la bahía. Si venían tres balsas es poco probable que únicamente dos hubieran quedado varadas y que la tercera sí hubiera podido tener el viento suficiente en sus velas para llegar a la playa.

Aunque las chalupas de los franceses hubieran podido dar alcance a las balsas indígenas, es también dudoso que hubieran logrado remolcarlas hacia sus barcos sin la avenencia de sus ocupantes. Una de las técnicas de defensa de los indígenas - que no dudaron en usar en los primeros momentos de la conquista en contra de los españoles - consistía en desatar los troncos de la balsa, desarticulando por completo la embarcación. Quien estuviera preparado para ejecutar esta acción sobreviviría fácilmente aferrándose a uno de los troncos sueltos, en cambio, los demás se hundirían en el agua (Estete, 1918: 318-319). El hecho de que los franceses remolcasen las balsas sin ningún tipo de resistencia indica que la relación fue consentida.

Finalmente, el último dato que demuestra la participación activa de los indígenas en el acercamiento a las embarcaciones fue el intento de ataque de otra balsa por parte de los franceses. Dicha balsa no solo pudo llegar a la playa, sino que salió victoriosa en su defensa al obtener ayuda de quienes se encontraban allí ${ }^{\text {. }}$ Este caso deja en claro que, en un caso de ataque, los balseros tenían las defensas suficientes para no ser asaltados. Aparentar jugar un rol pasivo en las relaciones con los franceses era una cuestión de vital importancia para los indígenas balseros, pues no solo estaban incurriendo en una actividad ilegal a la vista de los españoles, sino que el castigo hacia los indígenas era especialmente duro (multa, corte de cabello, destierro y trabajos forzados).

La estrategia de los navegantes de San Lucas de Colán fue doblemente exitosa, no solo al conseguir entrar en contacto con los franceses varados en la bahía de Paita, Ilevándoles la comida y el agua destinados al abastecimiento del puerto y seguramente recibiendo pago a cambio, sino que también lograron que las autoridades españolas no vieran en ese acto una conducta ilegal. Más allá de los testimonios descritos, no hay documentos en el Archivo Regional de Piura que den constancia de seguimiento al caso ni prueba de castigo a los implicados, ni siquiera identificación de los indígenas que participaron en el acercamiento a los franceses.

9 ARdP, Corregimiento, Caja N. 43, Exp. N. 0891, Expediente seguido por don Francisco Migueles sobre las embarcaciones francesas que han llegado a Paita, ff. 5v, 5r. 


\section{CONCLUSIONES}

La navegación indígena en América fue una actividad que alcanzó gran complejidad en época precolombina y que no solo perduró durante el periodo virreinal, sino que aumentó su práctica a partir del siglo XVI. Aunque estemos acostumbrados a pensar que las prácticas indígenas durante la época virreinal son pálidos reflejos de su referente prehispánico, este no es el caso de la navegación sobre el Pacífico. Específicamente en la costa norte del Perú y la de Ecuador, gracias a la tecnología de velas latinas o cuadras combinadas con guares, los indígenas de esta región establecieron relaciones comerciales a larga distancia.

Los españoles se vieron beneficiados de esta tecnología: en Paita, por ejemplo, las balsas indígenas eran ideales para el abastecimiento de agua y alimentos del puerto. Gran parte de la prosperidad de Paita y de toda la región del norte peruano y del sur ecuatoriano se debió a la participación indígena en el transporte de mercancías (Jaramillo, 2002: 217). Sin embargo, esta tecnología también contribuyó al contrabando al surtir barcos franceses que hacían la ruta desde Saint-Malo hasta el Lejano Oriente. Estas actividades legales e ilegales no pueden ser comprendidas a cabalidad sin la participación activa de los indígenas, quienes lograban tener gran capacidad de acción gracias a la práctica de la navegación con tecnología propia. De manera más general, estoy convencido de que la navegación en América, así se haya practicado con tecnología europea, no puede ser entendida sin comprender el papel activo jugado por los pueblos indígenas. Muchas veces el registro oficial que se guarda en los archivos no da cuenta de esto; no obstante, una mirada más cuidadosa sobre fuentes diversas mostrará de qué manera los pueblos indígenas se articularon a las redes de navegación.

Los indígenas que se dedicaban a la navegación gozaron de autonomía y riqueza económica, ya que su actividad les permitía comerciar y transportar mercancías por diferentes lugares. Los habitantes de San Lucas de Colán supieron aprovechar sus conocimientos y habilidades para negociar un lugar de preeminencia dentro de la sociedad virreinal. Lejos de una actitud derrotista frente al nuevo orden, los navegantes y comerciantes de Colán obtuvieron una posición de privilegio frente a las autoridades españolas.

Del lado español, estos también supieron aprovechar el conocimiento sobre navegación que tenían los indígenas y pusieron a su servicio las balsas de pueblos como Colán para abastecer a sus ciudades. A pesar de lo anterior, la navegación indígena también representaba un elemento peligroso para las autoridades españolas, pues, fuera de los registros oficiales, estas embarcaciones eran propicias para el contrabando. Los enemigos de España seguramente tenían conocimiento de poder explotar este factor, y el caso de las embarcaciones francesas en Paita en 1707 que se acaba de analizar no debió haber sido una excepción ni en el Caribe ni en el Pacífico ${ }^{10 .}$

10 Para explorar un caso de la relación entre los piratas y los indígenas en el Golfo de México, véase Favila Vázquez (2016: 184-225). 
Por último, es importante resaltar que si bien estaban en una posición aparentemente subordinada durante la época virreinal, en muchas ocasiones los indígenas en América retomaron sus conocimientos (como el de la navegación) para obtener beneficios colaborando con, o engañando a, las autoridades españolas.

\section{Agradecimientos}

Agradezco el apoyo académico de la Universidad Nacional Autónoma de México y del Museo Arqueológico Rafael Larco Herrera de Lima para que este trabajo fuera posible; asimismo, a Luis Millones, Renata Mayer, Ulla Holmquist y Diana Ramos Icanaqué por las valiosas indicaciones sobre el norte peruano; al personal del Archivo Regional de Piura y del Centro de Investigación y Promoción del Campesinado por su disposición; a Jessica Ortiz por sus correcciones en la paleografía; a Mariano Bonialian por su apoyo bibliográfico; a Colin McEwan por su ayuda para conseguir los permisos de las imágenes y a Ana Somohano Eres por sus consecutivas revisiones al texto final.

\section{Referencias citadas}

\section{Fuentes primarias}

Archivo Regional de Piura (ARdP)

ARdP, Causas ordinarias, Legajo 43, Exp. N. 0890, Visita de embarcaciones que entran y salen de Paita. Enero-julio, 1691

ARdP, Corregimiento, Caja N. 1, Exp. N. 0011, Deudas de don Diego de Belasco

ARdP, Corregimiento, Caja N. 4, Exp. N. 0344, Testamento de Colán, 1697

ARdP, Corregimiento, Caja N. 43, Exp. N. 0891, Expediente seguido por don Francisco Migueles sobre las embarcaciones francesas que han llegado a Paita

ARdP, Corregimiento, Caja N. 43, Exp. N. 0892, Expediente civil relacionado con la entrada y salida de embarcaciones del puerto de Paita, 1727

\section{Fuentes secundarias}

ALCEDO, A. de, 1788 - Diccionario geográfico-histórico de las Indias occidentales ó América, es a saber: de los Reynos del Perú, Nueva España, Tierra-Firme, Chile, y Nuevo Reyno de Granada, Tomo IV, 609 pp.; Madrid: Imprenta de Manuel Gonzalez.

ANDRITZKY, W., 1987 - Balsas de la costa norte del Perú antiguo y actual. Boletín de Lima, año 9, vol. 49: 33-41.

BENZONI, G., 1985 - La Historia del Nuevo Mundo (Relatos de su viaje por el Ecuador, 1547-1550), IV + 135 pp.; Guayaquil: Banco Central del Ecuador.

BONIALIAN, M. A., 2012 - El Pacífico hispanoamericano. Política y comercio asiático en el Imperio Español (1680-1784), 490 pp.; México, D. F.: El Colegio de México.

ELÍAS LEQUERNAQUÉ, J. P., 2008 - Don Sebastián de Colán y Pariña y sus ancestros: caciques de dos pueblos de la costa del corregimiento de Piura (s. XVI-XVII). Bulletin de l'Institut Français d'Études Andines, 37 (1): 151-161. 
ESTETE, M. de, 1918 - Noticia del Perú (1535). Boletín de la Sociedad Ecuatoriana de Estudios Históricos Americanos, tomo 1, n. ${ }^{\circ}$ 3: 312-335.

FAVILA VÁZQUEZ, M., 2016 - Veredas de mar y río. Navegación prehispánica y colonial en Los Tuxtlas, Veracruz, 286 pp.; México, D. F.: Universidad Nacional Autónoma de México.

HAKLUYT, R., 2015 - The prosperous voyage of worshipful Thomas Candish of Trimley in the County of Suffolk Esquire, into the South Sea, and from thence round about the circumference of the whole earth, begun in the year of our Lord 1586, and finished 1588. In: The Voyage of Sir Francis Drake Around the Whole Globe: 23-52; Londres: Penguin Classics.

HERNÁNDEZ, E., 1996 - Vocabulario en lengua castellana y mexicana de fray Alonso de Molina. Estudio de los indigenismos léxicos y registro de las voces españolas internas, XXIV + 457 pp.; Madrid: Consejo Superior de Investigaciones Científicas.

JARAMILLO, M., 2002 - El impacto de la apertura al comercio internacional sobre la economía regional del extremo norte peruano, 1780-1877. In: Estado y mercado en la historia del Perú (C. Contreras \& M. Glave, eds.): 215-249; Lima: Pontificia Universidad Católica del Perú.

JIMÉNEZ DE LA ESPADA, M., 1885 - Relaciones geográficas de Indias. Perú, Tomo II; Madrid: Ministerio de Fomento.

JUAN, J. \& ULLOA, A. de, 1748 - Relacion Historica del viage hecho de orden de S. Mag. a la America Meridional, Primera Parte, Tomo Primero, 404 pp.; Madrid: Antonio Marin.

MOYA ESPINOZA, R., 1994 - Breve historia de Piura. Tomo II, La Conquista en Piura, 380 pp.; Piura: Instituto Cambio y Desarrollo, Editorial Pachacutec.

REAL ACADEMIA ESPAÑOLA, 1726 - Diccionario de Autoridades, Tomo I (en línea). Disponible en http://web.frl.es/DA.html (consulta realizada el 6 de agosto de 2016).

ROSTWOROWSKI, M., 2004 - Testamento de don Luis de Colán, curaca en 1622. In: Obras completas de María Rostworowski, Volumen III. Costa peruana prehispánica: 181-218; Lima: Instituto de Estudios Peruanos.

SEARS, A. F., 1895 - The Coast Desert of Peru. Journal of the American Geographical Society of New York, vol. 27, n. ${ }^{\circ}$ 3: 256-271.

SPILBERGEN, J. van, 1906 - The East and West Indian Mirror, being an Account of Joris van Speilbergen's Voyage Round the World (1614-1617), and the Australian Navigations of Jacob Le Maire; Londres: The Hakluyt Society.

ZARAGOZA, J., 1885 - Viaje político-científico alrededor del mundo por las corbetas Descubierta y Atrevida al mando de los capitanes de navío D. Alejandro Malaspina y don José de Bustamante y Guerra desde 1789 a 1794, 683 pp.; Madrid: Imprenta de la viuda é Hijos de Abienzo.

ZÚÑIGA DE RIOFRÍO, P., 2011 - San Lucas de Colán, reliquia histórica y símbolo de transculturación. Mercurio Peruano, 524: 277-283. 


\section{Anexos}

\section{ARdP, Corregimiento, Caja N. 43, Exp. N. 0891, Expediente seguido por don Francisco Migueles sobre las embarcaciones francesas que han llegado a Paita, folios 1v y 1r}

Verso

Don Antonio Fernandez de Quiñones T[enien]te de este puerto de Paita y su partido.

Por quanto el día veinte de este presente mes de Henero dieron fondo en este dicho puerto dos Vageles Franceses que dicen llamarse el uno de Brillae o Brilhae cuio cauo o capitán es Don Luis Rorcreyel el otro la Confianza de que es Capitan Don Joseph Gerard, que salieron de la ciudad de samalon [Saint-Malo], y por los gravísimos perjurios e inconvenientes que de el trafico y comercio de la nación francesa en estas indias se sigue a los de Sevilla y Lima, a la causa pública y lo que es mas a su magestad defraudándosele sus reales derechos y disminuiendosele por ocasión de estas entradas prohividas por sus r[eale]s leies y cedulas de indias , y ultimam[en]te por bando de los señores presidente y oidores de la r[ea]l audiencia de Lima a cuio cargo es el govierno superior de estos reynos por vacante del señor virrey; el qual dicho bando se publicó en este dicho puerto a usanza de guerra. Por tanto arreglándome a dichas r[eale]s leies y bando prohivo, mando y defiendo que persona alguna no se atreva a comprar, trocar, cambiar ni en manera alguna negociar con los dichos franceses aunque sea a título y ro color de darles por sus géneros vastim[en]tos y por las mercaderías que los franceses llaman Bagatelas porque no se les an de dar en ninguna manera ni con ningún pretexto (porque para en caso de necesitar los tiene el govierno superior de la providencia) so pena de quatro mil pesos, y que se darán por extraviadas digo por descaminadas y decomiso las dichas mercaderías, de diestierro a Baldivia y de caer e incurrir los tales comerciantes en la indignación y de las demás penas y a percibimientos impuestas en el dicho bando a que me remito y so las mismas penas mando que ningúno sea osado a embarcarse a bordo de los dichos vageles, y que los 


\section{Reverso}

capitanes maestres dueños de vageles contramaestres arraeces ${ }^{11}$ de varcas, lanchas, canoas, barquillas y balsas no se atrevan a abordar ni llegar con sus embarcaciones maiores y menores a dichos vageles franceses. Ansimismo a los dueños mayorales y capataces requas que no carguen marcaderias algunas de los dichos franceses devajo de las mismas penas y que los indios dueños del agua observen lo mismo so pena de doscientos azotes, cortarles los cavellos y diez años de destierro, a sacar piedra a la isla de el Callao, cuyas penas se ejecutaran inmediatamente en las transgresiones. $=$ Y por quanto no ai modo de hacer zarpar dichas vageles ni otro de impedirles su comercio que celar y vigilar el desembarque de los generos y que no embarquen alimentos. Mando se paguen centinelas en las partes que convengan los quales devajo de la misma pena me darán aviso si se embarca o desembarca alguna cosa para proceder a lo que hubiere lugar y la misma participaren a los s[eñor]es jueces oficiales R[eale]s o sus thenientes todo lo qual devejo de las dichas penas se guarde cumpla y ejecute precisa e inviolablemente; y para que llegue a noticia de todos y que ning[un]o alegue ignorancia se publique este mi auto por bando en la forma acostumbrada así lo provei actue $\mathrm{Y}$ firme por falta de escriv[ano] con testigos que lo fueron el aiudante Fran[cisc]o González Leal, don Fernando Díaz Nieto y don Miguel Soriano $=$ fecho en este dicho puerto de Paita en veinte $y$ un días del dicho mes de henero de mil setecientos y siete años.

Firmas

11 Arraez: capitán de una embarcación árabe o morisca. 


\section{ARdP, Corregimiento, Caja N. 43, Exp. N. 0891, Expediente seguido por don Francisco Migueles sobre las embarcaciones francesas que han llegado a Paita, folios $5 v$ y $5 r$}

Verso

En el puerto de Payta en veinte y nuebe días

del mes de hen[ero] de mil setecientos y siete años. El s[eño]r d[o]n

Fran[cisc]o Migueles correx[id]or y just[ici]a m[aio]r De la ciudad de san

Miguel de Piura y ten[ien]te de Cap[ita]n Gen[eral] En ella y su

jurisdicción por su Mag[esta]d-. Dixo que oy como

a las siete de la mañana biniendo tres bal-

sas de agua del pueblo de Colán que traían hasta

quatrosientas botijas llegó una de estas balsas

con siento y quarenta a la playa de este puerto

de las dos que por falta de viento estaban dete-

nidas salieron dos chalupas de las naos fran-

zesas que están en la baia y las remolcaron y

llebaron p[ar]a sus navíos las quales an echo notable

falta a la providencia de la mucha gente que

ay oy en dicho puerto de las embarcaciones que

ay del tráfico de este mar que están así mismo

dadas fondos y pasaron a yntentar los dichos franceses

llebarse la balsa que esta descargando sus botijas

en la playa siendo necesario impidirselo con al-

gunas [...] los vecinos y personas que se alla-

ron presentes y p[ar]a que pueda constar al real y su-

perior gov[ierno] y mando que el pres[ente] es[criba]no Me lo de p[o]r-

testimonio A continuación de este auto asi lo provey

y firme.

Don Francisco Migueles [rúbrica] ante mi Don Ant[oni]o R[odri]g[ue]z de las Varillas, escribano P[ubli]co y de Cab[ild]o [rúbrica]. 


\section{Reverso}

Y en cumplim[iento] de lo mandado por el auto antes escrito yo el esc[iba]no p[ublic]o De cav[il]do minas y Rexistros

y hac[ien]da Real de esta jurisdicción doy fe y berdadero testimonio como oy veinte y nueve días del mes de henero de setescientos y siete a las siete de la mañana estando parado en la playa bi que una de las varcas con las que andan en esta baía los franceses que estaban en ella se llevaron a una balsa que venía cargada de botijas de agua para el abasto de este puerto y la remolcó y llebaron para uno de sus navíos y dejándola ya serca de ellos bolvia p[ar]a tierra la dicha barca a yntentar llevarse otra balsa que estaba descargando sus botijas con las cajas de los vestidos con cuyo motibo paso don Pablo Concha cavallero del orden de Calatraba y proveedor Gen[eral] De este mar con otras personas a la dicha balsa y Dijo A los franceses se rretirasen $Y$ dejasen el agua que era p[ar]a el pueblo y que no podían traer orden de los capitanes para llebarla con cuya diligencia se rretiraron los dichos franceses y se hicieron a la mar coxieron otra balsa que venía con botijas de agua y la rremolcaron como la primera todo lo qual a sido p[ubli]co y notorio en testimonio dello lo signo y firmo.

Testado $=$ qual $=$ no Vale $=$ En testimonio [signo del escribano] i? Don Ant[oni]o R[odri]g[ue]z de las Varillas, escribano P[ubli]co y de Cab[ild]o [rúbrica]. 